\title{
Platelet counting using the Coulter electronic counter
}

\author{
M. J. EGGLETON AND A. A. SHARP \\ From the Radcliffe Infirmary, Oxford
}

SYNOPSIS A method for counting platelets in dilutions of platelet-rich plasm using the Coulter electronic counter is described. ${ }^{1}$ The results obtained show that such platelet counts are at least as accurate as the best methods of visual counting. The various technical difficulties encountered are discussed.

Platelet counting by visual methods, either by direct or indirect counting, is recognized to be inaccurate. Yet it must be admitted that these methods, although tedious, have served well for deciding low, normal, or high blood platelet counts in clinical haematology. Further, with experienced observers and by using phase-contrast microscopy, the error of these visual methods can be substantially reduced (Brecher, Schneiderman, and Cronkite, 1953).

Yet, when platelet counts are required on highdensity suspensions for experimental purposes, e.g., radioactive or biochemical studies, or when the numbers of platelets in numerous samples require to be counted, visual methods are tedious and timeconsuming. Therefore it was decided to attempt to apply the principle of electronic counting to this problem and it is the purpose of this paper to describe the investigations that have been made into this problem and to describe one method for counting platelets using the Coulter electronic counter.

\section{THE PRINCIPLE OF CELL OR PARTICLE COUNTING USING THE COULTER ELECTRONIC COUNTER}

If particles or cells are passed through a very small aperture along with an electric current, each particle or cell will produce a temporary resistance to the flow of current as it transiently occupies the aperture. The larger the volume of the cell, the greater the resistance. This resistance can be converted to a proportional signal which can be detected electronically. Therefore, if a known volume of a suspension of particles or cells is passed through the aperture, it is possible to count electronically the

Received for publication 11 October 1962

'Since this paper was submitted for publication two important papers referring to similar methods have been published.

Girling, J. H. (1962). J. med. Lab. Tech., 19, 168.

Sipe, C. R., and Cronkite, E. P. (1962). Ann. N.Y. Acad. Sci., 99, 262. number of cells or particles in this volume. Large cells, such as red cells and white cells, produce a relatively large signal and are counted by this $z$ method using an aperture of $100 \mu$ in diameter. As the volume of platelets varies from 2 to $30 \mathrm{c} \mu$., i.e., $\stackrel{\Im}{工}$ $1 / 40$ to $1 / 3$ of a red cell, the resistance they provide $\vec{\epsilon}$ is smaller. So to enhance the signal produced by these small cytoplasmic fragments it is necessary both to reduce the size of the aperture to 70 or $50 \mu$ and to increase the current flowing through the aperture (aperture current-setting). When this is done the signal produced by dust particles and by the inherent electronic background noise is very close to that produced by platelets. The counter is, however, so designed that it is possible to eliminate the noise and small particle signals and still measure the signals produced by the platelets by increasing the threshold or discriminator voltage. Thus, only signals of a sufficient size are counted.

\section{METHODS}

PLATELET-RICH PLASMA Venous blood, $9 \cdot 7 \mathrm{ml}$, , collected 을 by careful venepuncture using a siliconized syringe, is $D$ placed in a siliconed, graduated centrifuge tube containing 음. $0.3 \mathrm{ml} .4 .5 \%$ disodium E.D.T.A. (ethylene diamine tetra- $\mathrm{N}$ acetic acid) and mixed. The blood is spun at 900 r.p.m. for 15 minutes $(60 g)$ and the supernatant plasma $N$ separated.

VISUAL PLATELET COUNTS (Brecher, Schneiderman, and Cronkite, 1953) A one-twentieth dilution of the sample to be counted is made in a conventional white cell pipette $\bar{\Phi}$ with filtered $1 \%$ ammonium oxalate and mixed by a $\stackrel{+}{+}$ vibration agitator for three minutes. Platelet counting chambers (Messrs. Hawksley Limited, Improved Neu-

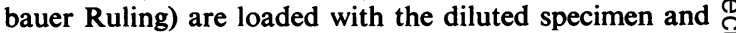
allowed to stand for 30 minutes in a moist chamber $\overrightarrow{\mathbb{D}}$ before counting. All counts are performed using phase contrast microscopy with a magnification of $\times 320$. 
The number of platelets in 80 squares (1 square $=1 / 400$ sq. $\mathrm{mm}$.) is counted in duplicate.

DILUTION OF PLATELET-RICH PLASMA FOR ELECTRONIC COUNTING Platelet-rich plasma, $20 \mathrm{c} . \mathrm{mm}$., is added to $100 \mathrm{ml}$. particle-free $0.85 \%$ saline giving a $1 / 5,000$ dilution.

ELECTRONIC COUNTING The $1 / 5,000$ dilution is counted using the Coulter counter with a $50 \mu$ orifice, aperture current setting 7 , and threshold 25 . Platelet-free saline is counted to determine the background count due to electronic noise and debris and this value subtracted from the counts obtained for the platelet-containing dilutions.

PACKED CELl volume The packed cell volume of the whole blood is determined using the Hawksley highspeed haematocrit centrifuge.

PARTICLE-Free SALINE Normal $0.85 \%$ saline is filtered through a sintered glass filter (Gallenkamp ref. No. $225 \times 3)$ until the particle count, as measured by the electronic counter, is below $5,000 /$ c.mm. Scrupulous attention to cleanliness is imperative at all stages and saline is freshly filtered before each batch of counts.

\section{RESULTS}

The effect of varying aperture current setting and threshold on electronic counts of a dilution of platelet-rich plasma is illustrated in Fig. 1.

The correlation between visual counts and electronic counts on platelet-rich plasma is illustrated in Fig. 2.

Platelet counts obtained for platelet-rich plasma were corrected to whole blood counts using the following formula:

Whole blood count $=$ platelet-rich plasma count $\times$

$$
\frac{(100-\text { P.C.V. })}{100}
$$

The relationship of this calculated value to the visual count on the original whole blood sample is shown in Fig. 3.

The accuracy of replicate visual counts and electronic counts on a single platelet-rich plasma is

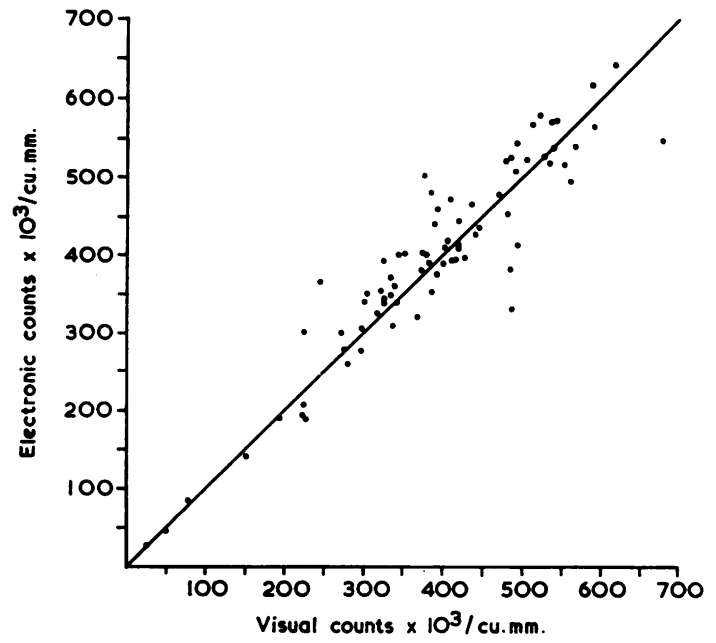

FIG. 2. The relationship of electronic to visual plateletrich plasma counts.

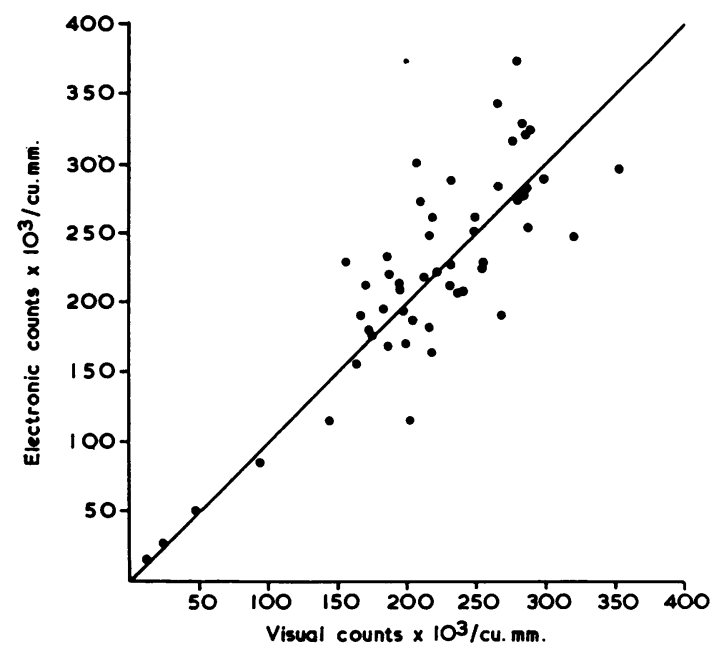

FIG. 3. The relationship of corrected electronic plateletrich plasma counts to visual whole blood counts.
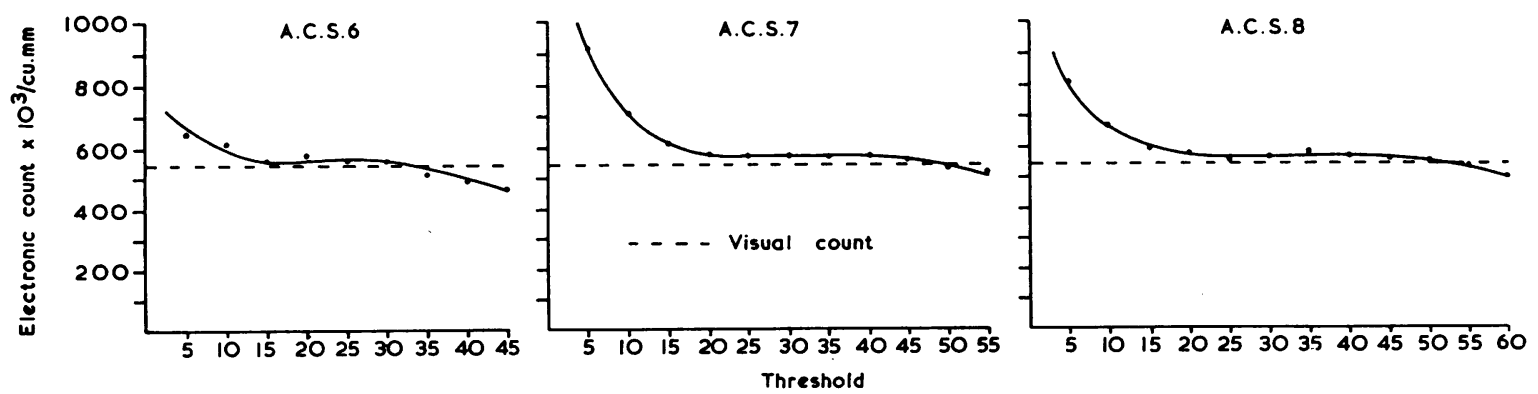

FIG. 1. The effect of varying aperture current setting and threshold voltage on electronic platelet counts. 
illustrated in Table I. Each count represents a separate dilution of the original plasma and the dilutions and counts were made by four persons. The results have been analysed to show the machine error of the Coulter counter and the human errors of the pipetting and counting in both methods (Table I). These indicate that the machine itself is not a significant source of error but that the major error of the method is dependent on the process of dilution. Also there is no significant difference in the accuracy of electronic counting and visual counting.

\section{TABLE I}

REPLICATE ELECTRONIC AND VISUAL

PLATELET COUNTS ON 16 SEPARATE DILUTIONS OF PLATELET-RICH PLASMA

\begin{tabular}{|c|c|c|c|c|}
\hline Count I & Count II & Count III & Mean & per c.mm. \\
\hline $\begin{array}{l}68,323 \\
71,460 \\
69,142 \\
65,633 \\
70,800 \\
73,122 \\
80,336 \\
78,580 \\
56,730 \\
64,770 \\
67,240 \\
65,152 \\
71,830 \\
65,380 \\
67,015 \\
66,946\end{array}$ & $\begin{array}{l}68,951 \\
71,482 \\
68,844 \\
65,251 \\
71,161 \\
72,626 \\
80,361 \\
78,075 \\
56,351 \\
64,461 \\
66,844 \\
65,194 \\
71,542 \\
65,041 \\
66,904 \\
66,673\end{array}$ & $\begin{array}{l}68,134 \\
71,085 \\
68,681 \\
65,652 \\
71,600 \\
72,921 \\
80,541 \\
78,221 \\
56,076 \\
64,155 \\
67,353 \\
64,931 \\
71,783 \\
65,163 \\
66,960 \\
66,176\end{array}$ & $\begin{array}{l}68,469 \\
71,343 \\
68,889 \\
65,512 \\
71,187 \\
72,890 \\
80,413 \\
78,293 \\
56,386 \\
64,462 \\
67,146 \\
65,093 \\
71,718 \\
65,195 \\
66,960 \\
66,598\end{array}$ & $\begin{array}{l}508,000 \\
514,000 \\
507,000 \\
495,000 \\
545,000 \\
577,000 \\
574,000 \\
590,000 \\
514,000 \\
505,000 \\
565,000 \\
500,000 \\
550,000 \\
609,000 \\
568,000 \\
591,000\end{array}$ \\
\hline
\end{tabular}

Analysis of Variance

Electronic counts Standard deviations (S.D.) between individual counts on same dilution, $i . e$, machine error $=165$

S.D. between different dilutions of same platelet sample, i.e., dilution error $=5,682$

Visual counts S.D. between different dilutions of same platelet sample $=3,822$

The results obtained by counting known dilutions of a concentrated platelet suspension are illustrated in Fig. 4. The fall-off in the curve obtained with counts over $1,400,000 \mathrm{c} . \mathrm{mm}$. is probably due to the coincidence of more than one platelet passing through the aperture at one time. Coincidence correction factors have not been determined as with suspected counts of over 1 million it would appear simpler to count a 1/50,000 dilution of the platelet-rich plasma.

Counting platelets by the electronic method has not been straightforward. Blockage of the $50 \mu$ aperture has been the greatest nuisance during these experiments. Such blockages may be partial and not easily detectable.

Certain manufactured apertures produce a high 'noise' signal level either due to some inherent defect in manufacture or due to the presence of a small crack in the glass around the aperture. When this

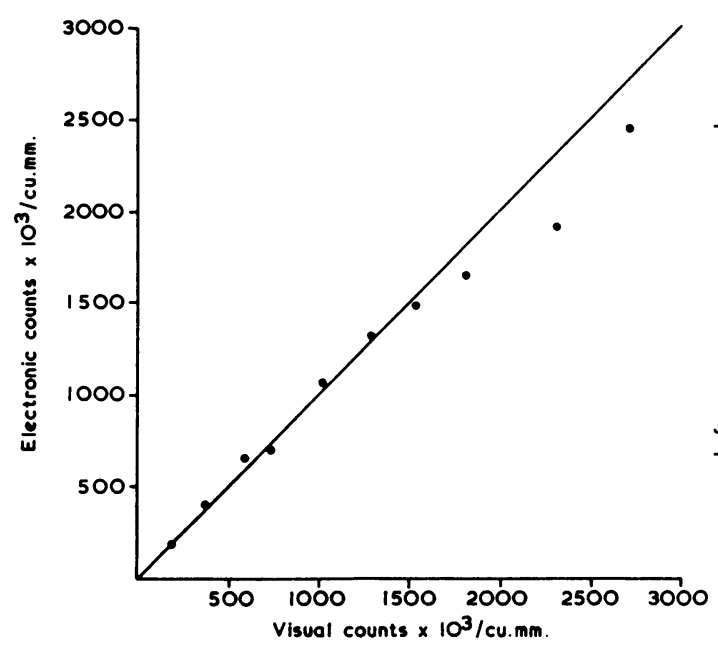

FIG. 4. Electronic platelet counts on known dilutions of $\vec{a}$ concentrated plasma suspension.

occurred the division between platelet signals ande 'noise' was too small. The only solution has been tow discard the faulty tube and test other aperture tubes until a suitable one was found.

Platelets can be counted using a $70 \mu$ aperture but the plateaux of the calibration curves were lesso satisfactory and for this reason the $50 \mu$ aperture waso preferred.

In our hands E.D.T.A. has proved to be a more satisfactory anticoagulant than citrate when compared by calibration curves and visual counts.

The time and speed of spinning whole blood to separate the platelet-rich plasma is critical. Eveno using the suggested values, 15 minutes at 900 r.p.m. $(60 \mathrm{~g})$, significant numbers of platelets have been lost when spinning certain samples. This pheno-o

\section{TABLE II}

REPEATED ELECTRONIC PLATELET COUNTS ON ONE SAMPLE OF PLATELET-RICH PLASMA USING 'LARGE' AND 'SMALL' COUNTING VOLUMES

\begin{tabular}{llll}
$I \mathrm{ml}$. Counting Volume & \multicolumn{2}{c}{ Small Counting Volume } \\
\hline $\mathbf{4 5 , 8 6 1}$ & 46,196 & 3,981 & 3,955 \\
$\mathbf{4 6 , 5 6 6}$ & 46,474 & 4,952 & 3,946 \\
$\mathbf{4 6 , 1 0 1}$ & 45,672 & 4,021 & 4,001 \\
45,813 & 46,105 & 3,981 & 4,021 \\
$\mathbf{4 6 , 2 6 8}$ & 45,539 & 3,911 & 4,125 \\
46,105 & 45,055 & 3,962 & 3,896 \\
45,547 & 45,441 & 4,016 & 4,095 \\
45,956 & 45,021 & 4,005 & 3,935 \\
46,605 & 45,188 & 3,974 & 4,011 \\
46,091 & 44,510 & 4,065 & 3,941 \\
Mean & 45,806 & Mean & 4,000
\end{tabular}

Standard deviation Large volume $(1 \mathrm{ml})=$. Small volume $=67.85(678.5)$ 
menon is probably due to an imperfect venepuncture causing platelet clumping and subsequent spinning out of the aggregates.

The Coulter counter may be used to count the particles in $0.5 \mathrm{ml}$. of fluid or in a volume approximately one tenth of this. The variations using the different volumes have been compared on the same blood sample (Table II). The use of the smaller volume has resulted in a quicker turnover and fewer spoilt counts due to the aperture becoming totally or partially blocked during the counting period.

\section{DISCUSSION}

Attempts to count platelets in dilutions of lysed whole blood have been unsuccessful as the lysed red cell ghosts can be detected and counted by this apparatus.

The technique of counting platelet-rich plasma has been successful but is as time-consuming as any direct visual counting method, and it is only when counts have to be done on several dilutions or on several blood samples that time and effort can be saved.

The results obtained show that platelets in plateletrich plasma can be counted electronically at least as well as by visual methods, and that it is possible to correlate platelet-rich plasma platelet counts to whole blood platelet counts by using the packed cell volume as the correcting factor.

The error of replicate counts on any given dilution is small (Table I) and it is apparent that the major error in this method lies in the preparation of the $1 / 5,000$ dilution of the platelet-rich plasma (Table I). Therefore, until some form of automatic dilution apparatus is available the error of platelet counting by electronic methods would appear to be of the same order as visual counting.

Before complete reliance can be placed on electronic counts a standard of known particle size and number must be devised to test the counter before each series of counts. Such a standard is desirable for electronic red and white cell counts as well as for platelet counts. Suspensions of particles of known size are available and are being tested but so far no reliable standard has been devised.

In conclusion, the results show that it is possible to count platelets in suspension with acceptable accuracy using the Coulter electronic counter. No doubt better techniques will be soon developed and direct platelet counts of whole blood samples will be possible.

We wish to thank Coulter Electronic Limited for their generous help; Mr. D. Goodchild for his advice and encouragement; and Dr. M. G. Bulmer of the Department of Biometry, Oxford University, for advice on statistical analysis of results.

\section{REFERENCE}

Brecher, G., Schneiderman, M., and Cronkite, E. P. (1953). Amer. J. clin. Path., 23, 15. 